\title{
Artemisinin (Qinghaosu): a mesmerizing drug that still puzzles
}

\author{
ZHOU Bing \\ State Key Laboratory of Membrane Biology, School of Life Sciences, Tsinghua University, Beijing 100084, China
}

Received October 16, 2015; accepted October 19, 2015; published online October 23, 2015

Citation: Zhou B. Artemisinin (Qinghaosu): a mesmerizing drug that still puzzles. Sci China Life Sci, 2015, 58: 1151-1153, doi: 10.1007/s11427-015-4955-8

The awarding of the 2015 Nobel Prize to Chinese scientist YouYou Tu created quite a stir in the media and scientific community. This award is the first Nobel Prize in natural sciences to a domestic Chinese scientist, and came at a time when the whole country was asking: who and when will the first domestic Chinese scientist receive this honor? Although long anticipated and well deserved, this event certainly arrived earlier than many expected.

The World Health Organization classifies malaria as one of the three major infectious diseases worldwide. Each year it affects no less than one hundred million people and kills more than half a million of them, mostly children. Malaria used to be rampant in a large part of southern China in the not too distant past. The arrival of the quinine class of drugs (such as chloroquine), initially found in the bark of Cinchona trees, a plant grown in South America, helped treat and eradicate this dreadful disease in most regions of China as well as some other parts of the world (such as the southern Europe). However, resistance started to develop against quinine and other antimalarial drugs. During the latter part of the Vietnam War, in late 1960s to early 1970s, malarial infections resulted in huge losses of military personnel on both sides of the conflict even with the help of some of then commonly used antimalarial drugs. Against this backdrop, the discovery of artemisinin (Qinghaosu) was the result of coordinated efforts of a large team of Chinese scientists organized by Chinese government in late 1960s to early 1970 s, in response to a request by the North Vietnamese to develop a new and more effective antimalarial drug. A key finding was made when Tu's group improved the extraction

email: zhoubing@mail.tsinghua.edu.cn method and revealed that the wormwood plant, Artemesia annua, contains a highly effective compound that can completely inhibit malarial parasites. This key information immediately shifted the research focus of many other groups, resulting in the later collaborative isolation and identification of artemisinin [1-2]. Subsequently, a set of artemisinin derivatives (the first generation artemisinin drugs) with some better pharmacological properties, including dihydroartemisinin, artemether, artesunate and arteether, were produced (Figure 1).

Despite the recent media frenzy surrounding artemisinin, few realize that there are more unknown than known about this life saving chemical. One of the most critical questions is how this miracle drug works. Unfortunately after so many years, little is known regarding how it inhibits malarial growth. Different theories come and go, and the focus of attention has been shifting every 5-10 years or so, leaving this issue very controversial and in a state of confusion [3,4]. After the initial efforts of modifying artemisinin, mostly made by Chinese scientists, later generations of drugs based on artemisinin may have very different backbones (Figure 1). These artemisinin derivatives or analogues all contain the endoperoxidic bond, the pharmaceutically active part of artemisinin drugs. Conventional thinking about drug action hypothesizes a target protein, in the malarial parasite inhibited by artemisinins. However, it is really remarkable and in my opinion even inconceivable how these drastically variable molecules, except for their sharing of the endoperoxidic bridge, can all be highly potent and specific towards a single protein within malaria parasites. Drugs usually only work in very specific configurations of the atoms, however both the right and left mirror images 

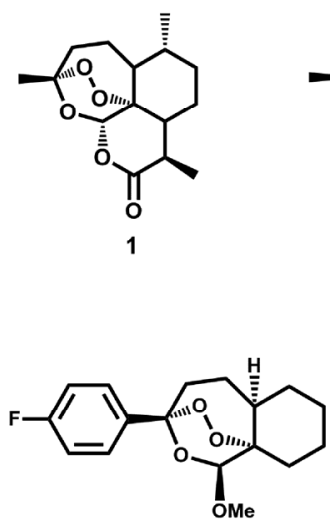

$5 a$

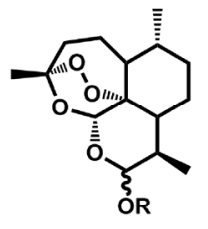

2

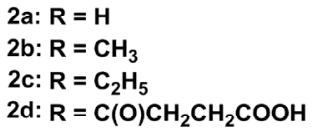

2d: $\mathrm{R}=\mathrm{C}(\mathrm{O}) \mathrm{CH}_{2} \mathrm{CH}_{2} \mathrm{COOH}$

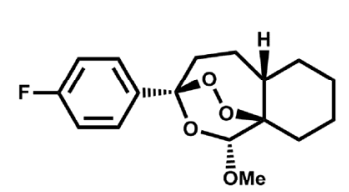

5b

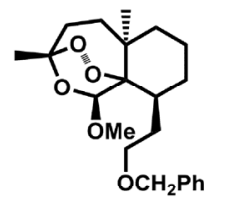

3

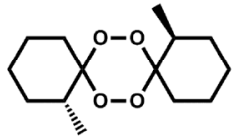

4

Figure 1 Structures of artemisinin and some artemisinin-based antimalarial compounds. The endoperoxide bridge, shared by all these compounds, is the key pharmacophore. 1, Artemisinin; 2a, dihydroartemisinin(DHA); 2b, artemether; 2c, arteether; 2d, artesunate; 3 , An analogue with close structure to artemisinin; 4, An antimalarial tetraoxane; 5a, 5b Enantiomers with similar activities against malaria parasites; 6, OZ439 (in clinical trial).

(enantiomers) of artemisinins appear equally effective. There is no doubt that artemisinins represent an amazingly unique class of molecules for which we have no prior experience in understanding at the molecular and cellular level. It is no wonder that so far nobody is certain how they work!

One of the major theories trying to explain the action of artemisinins is the heme model. Though details may vary, in this model, heme is expected to interact with artemisinin and then generate damage in places such as vacuoles in the cell. This theory had been a favorite for many years since heme can readily react with artemisinins in chemistry, and it is natural to link heme to erythrocytes because malaria parasites at certain stages indeed accumulate a lot of heme in the form of hemozoin, a detoxified and insoluble crystalline form of heme. However, no convincing functional data support this hypothesis and some data are even not favorable to this model. For example, Ro40-4388, a protease inhibitor blocking haemoglobin degradation, displays an antagonistic effect with chloroquine, but no interactions with artemisinin. These results suggest that heme interaction is not necessary for the antimalarial activity of artemisinin. In addition, during the tiny ring and gametocyte stages of the malarial parasite, when catabolism of hemoglobin to heme does not obviously take place, artemisinins are equally effective against these stages of the malarial parasites. Another similar model proposed that the action of artemisinins is mediated by iron in an uncertain form such as free iron, heme (heme contains an iron atom) or as Fe-S. Other hypotheses include specific protein targets (TCTP, Pfmdrl, Pfcrt and PfATP6) for artemisinins. Most recently compelling evidence links the K13-propeller protein of Plasmodium falciparum with "artemisinin resistance" in people [5]. Mutations in K13 protein in the parasites enable delayed malarial clearance in infected individuals, a phenomenon arguably labeled as "artemisinin resistance". However, parasites carrying these mutations are sensitive to the action of artemisinins in cell culture studies under constant drug pressure [6], suggesting that direct effects on K13 may not be a mechanism of the action of artemisinins. One possible explanation is that these mutant parasites may be more tolerant to stress compared to wild type malaria parasites. Indeed, a high recrudescence (reoccurrence) rate is often linked with short term treatment of malaria with single-drug artemisinins, suggesting that the parasite growth is quickly suppressed by artemisinins but cell death does not immediately occur. In this case, it is possible that K13 mutants are more resistant to death when dormant, explaining the differences between the results in cell culture studies and in people with K13 mutant parasites.

My research group has utilized the yeast, Saccharomyces cerevisiae, in combination with direct study of malarial parasites and other types of cells such as mammalian cells, to study the mechanism of action of artemisinins [7]. The yeast model organism serves as a platform to identify the possible biological effects of artemisinins which can be tested in parasites and mammalian cells. We found that the mitochondria of the yeast and subsequently of the malarial parasites are highly susceptible to the action of artemisinins. When purified mitochondria of the yeast and malarial parasites were subject to very low levels of artemisinin (several $\mu \mathrm{mol} \mathrm{L} \mathrm{L}^{-1}$ or even $100 \mathrm{nmol} \mathrm{L}{ }^{-1}$ for parasite mitochondria) treatment, almost instant depolarization of the membrane occurred, while the mammalian mitochondria could tolerate more than $100 \mu \mathrm{mol} \mathrm{L}{ }^{-1}$ artemisinins without observable effects [8]. We do not know yet what causes these differences but are actively working to unravel this mystery. Regarding the role of heme, we found when reacting with artemisinins, it appears to exert a general damaging effect on the cell, much less potent as well as less specific than the mitochondrial membrane depolarizing action of artemisinins [9]. These two different actions can be utilized to explain respectively the different properties of artemisinins 
against malarial parasites and cancer cells: one is very robust and selective, via membrane depolarization, whereas the other one, mediated by heme, is more general and much less potent.

Overall, despite an exciting story, as the media has reported, some of the details of artemisinin discovery are controversial. It is less known that there remain many further stories about artemisinins to be told. How do artemisinins, a unique class of molecules, achieve their biological effects? Are there other applications of artemisinins? Notably, there are already indications that artemisinins may find applications in some other maladies including other infections, auto-immune diseases and even cancer [10]. When all the gleaming lights and glory about the Nobel Prize settle down, we should probably ask ourselves how to address the other half of the story, solve the remaining mysteries, and take artemisinin research to a new level in our endeavors to understand this mesmerizing drug.

1 Qinghaosu Antimalaria Coordinating Research Group. Antimalaria studies on Qinghaosu. Chin Med J, 1979, 92: 811-816

2 Qinghaosu Coordinating Research Group. A new sesquiterpene lactone-qinghaosu. Chin Sci Bull, 1977, 3: 142
3 Sun C, Li J, Zhou B. Mechanism of action of artemisinins: a long unsettled challenge. Sci China Life Sci (in Chinese), 2012, 42: 345-354

4 Li J, Zhou B. Biological actions of artemisinin: insights from medicinal chemistry studies. Molecules, 2010, 15: 1378-1397

5 Ariey F, Witkowski B, Amaratunga C, Beghain J, Langlois AC, Khim N, Kim S, Duru V, Bouchier C, Ma L, Lim P, Leang R, Duong S, Sreng S, Suon S, Chuor CM, Bout DM, Ménard S, Rogers WO, Genton B, Fandeur T, Miotto O, Ringwald P, Le Bras J, Berry A, Barale JC, Fairhurst RM, Benoit-Vical F, Mercereau-Puijalon O, Ménard D. A molecular marker of artemisinin-resistant Plasmodium falciparum malaria. Nature, 2014, 505: 50-55

6 Straimer J, Gnädig NF, Witkowski B, Amaratunga C, Duru V, Ramadani AP, Dacheux M, Khim N, Zhang L, Lam S, Gregory PD, Urnov FD, Mercereau-Puijalon O, Benoit-Vical F, Fairhurst RM, Ménard D, Fidock DA. Drug resistance. K13-propeller mutations confer artemisinin resistance in Plasmodium falciparum clinical isolates. Science, 2015, 347: 428-431

7 Li W, Mo WK, Shen D, Sun LB, Wang J, Lu S, Gitschier JM, Zhou B. Yeast model uncovers dual roles of mitochondria in action of artemisinin. PLoS Genet, 2005, 1: e36

8 Wang J, Huang LY, Li J, Fan QW, Long YC, Li Y, Zhou B. Artemisinin directly targets malarial mitochondria through its specific mitochondrial activation. PLoS One, 2010, 5: e95822

9 Sun C, Li J, Cao Y, long GB, Zhou B. Two distinct and competitive pathways confer the cellcidal actions of artemisinins. Microb Cell, 2015, 2: 14-25

10 Ho WE, Peh HY, Chan TK, Wong WS. Artemisinins: pharmacological actions beyond anti-malarial. Pharmacol Ther, 2014, 142: 126-139

Open Access This article is distributed under the terms of the Creative Commons Attribution License which permits any use, distribution, and reproduction in any medium, provided the original author(s) and source are credited. 